\title{
Inquérito soroepidemiológico para pesquisa de infecções por arbovírus em moradores de re- serva ecológica
}

Serological survey on arbovirus infection in residents of ecological reserve

Nicolina S Romano-Lieber ${ }^{\mathrm{a}}$ e Lygia B Iversson ${ }^{\mathrm{b}}$

a Departamento de Prática de Saúde Pública da Faculdade de Saúde Pública da Universidade de São Paulo (FSP/USP). São Paulo, SP, Brasil. 'b Departamento de Epidemiologia da FSP/USP. São Paulo, SP, Brasil 


\title{
Inquérito soroepidemiológico para pesquisa de infecções por arbovírus em moradores de reserva ecológica* Serological survey on arbovirus infection in residents of ecological reserve
}

\author{
Nicolina S Romano-Lieber ${ }^{\mathrm{a}}$ e Lygia B Iversson ${ }^{\mathrm{b}}$ \\ aD epartamento de Prática de Saúde Pública da Faculdade de Saúde Pública da U niversidade de São \\ Paulo (FSP/USP). São Paulo, SP, Brasil. ' ${ }^{\text {D }}$ epartamento de Epidemiologia da FSP/USP. São Paulo, SP, Brasil
}

\section{Descritores}

Infecções por arbovírus,

epidemiologia\#. Arbovírus, imunologia\#. Reservas naturais. Fatores de risco. Soroepidemiologia, inquérito.

\section{Keywords}

Arbovirus infections, epidemiology". Arboviruses, imunology". Natural reservation. Risk factors.

Seroepidemiology, survey.

\section{Resumo}

\section{Objetivo}

Inquéritos sorológicos têm evidenciado ampla circulação de arbovírus causadores de doença humana na Região do Vale do Ribeira, São Paulo, Brasil. Com o propósito de estabelecer a prevalência de infecções por esses agentes em reserva ecológica, localizada naquela área, pesquisou-se a presença de anticorpos, bem como suas possíveis associações com características individuais e familiares dos investigados. Métodos

Pesquisaram-se anticorpos para os antígenos dos vírus Rocio (ROC), Ilhéus (ILH), encefalite de St. Louis (SLE), encefalites eqüinas do leste (EEE), oeste (WEE) e venezuelana (VEE), em 182 pessoas pertencentes a 58 famílias residentes na Estação Ecológica de Juréia-Itatins, utilizando-se testes de inibição de hemaglutinação e neutralização com redução de placas. Usou-se Mac-Elisa para pesquisar anticorpos IgM para os vírus ROC, ILH e EEE.

\section{Resultados}

Foi observada a presença de anticorpos para todos os arbovírus testados, com exceção do vírus WEE. A prevalência total de anticorpos foi 26,9\% (21,4\% para alfavírus e 12,6\% para flavivírus). Não foram encontrados anticorpos IgM. Entre as várias características pesquisadas dos indivíduos e de suas famílias, a idade, a ocupação, a naturalidade e o hábito de entrar na mata mostraram-se estatisticamente associados a infecções por arbovírus $(\mathrm{p}<0,05)$.

\section{Conclusões}

Existe intensa circulação de arbovírus patogênicos, especialmente do alfavírus VEE, na população estudada. Aparentemente, a principal forma de exposição a vetores de arbovírus nessa população é o hábito de entrar na mata. Sugerem-se outras investigações sobre a responsabilidade de aves atuando como amplificadores de vírus dentro dos domicílios.

\footnotetext{
Abstract

Objective

Serological inquires conducted in the Ribeira Valley, S. Paulo State, Brazil, showed an intense circulation of pathogenic arboviruses in the region. The goal was to verify the prevalence of arboviral infections in people living at the local ecological, and its potential association with these population' individual and familiar characteristics.
}

Correspondência para/Correspondence to: Nicolina S. Romano-Lieber

Av. Dr. Arnaldo, 715

01246-904 São Paulo, SP, Brasil

E-mail: nicolina@usp.br
*Baseado na tese de doutorado apresentada à Faculdade de Saúde Pública, USP em 1996.

Subvencionado parcialmente pelo Conselho Nacional de Desenvolvimento Científico e Tecnológico (CNPq Processo 203098-90.0).

Edição subvencionada pela Fapesp (Processo n 00/01601-8).

Recebido em 27/1/1999. Reapresentado em 5/10/1999. Aprovado em 8/11/1999. 


\begin{abstract}
Methods
The study was carried out among 182 persons of 58 families to identify the presence of antibodies to the following viruses: Rocio (ROC), Ilheus (ILH), Eastern equine encephalitis virus (EEE), Western equine encephalitis virus (WEE), Venezuelan equine encephalitis virus (VEE) and St. Louis encephalitis virus (SLE). Inhibition hemagglutination test and plaque reduction neutralization test were the laboratory assays of choice. MAC-ELISA was used to identify IgM antibodies to ROC, ILH and EEE viruses.

Results

The prevalence of antibodies was 26.9\% (21.4\% to alphavirus and $12.6 \%$ to flavivirus). There were no antibodies to WEE virus. IgM antibodies were not observed suggesting no recent infection in study population. Among the characteristics investigated, age, occupation, place of birth and the habit of going into the forest were shown to be statistically associated with arboviral infection $(p<0.05)$.

Conclusions

It was observed an intense circulation of pathogenic arboviruses, especially VEE. It seems the habit of going into the forest is the most important factor to this population exposure to the mosquito vectors of arboviruses. The results suggest the need of further investigation to clarify the role of birds as arbovirus infection amplificators indoors.
\end{abstract}

\section{INTRODUÇÃO}

O interesse no conhecimento dos arbovírus e das infecções por eles causadas, no Estado de São Paulo, acentuou-se com a ocorrência de epidemia de encefalite, causada pelo vírus Rocio (ROC) na década de 70, na região do Vale do Ribeira. Tratavamse dos primeiros casos de doença humana autóctone, causada por esses agentes etiológicos no Estado, desde a ocorrência de casos de febre amarela na década de $50 .{ }^{19}$

Diversos arbovírus, alguns patogênicos para o homem, foram isolados naquela região durante a epidemia e em anos posteriores. ${ }^{1,2,4,6,16}$ Estudos soroepidemiológicos mostraram circulação também na população humana de arbovírus sabidamente patogênicos, como bunyavírus Caraparu, flavivírus ROC, Bussuquara, Ilhéus (ILH), da febre amarela e da encefalite de St. Louis (SLE) ${ }^{7,16}$ e alfavírus causadores das encefalites eqüinas do leste (EEE), do oeste (WEE) e venezuelana (VEE). ${ }^{8}$ A transmissão urbana dos vírus ROC e Caraparu foi sugerida pela presença de anticorpos para esses agentes, verificada em soros de escolares residentes em zona urbana na região, sem hábito de freqüência a ambiente silvestre. ${ }^{9}$

A epidemia causada pelo vírus ROC, a primeira de encefalite por arbovírus assinalada no Brasil, acometeu mais de mil pessoas com um saldo de uma centena de óbitos e duas centenas de indivíduos com seqüelas graves, entre os anos de 1975 e $1977 .{ }^{11}$ Após esse período epidêmico, outros casos de doença humana grave causada pelo agente foram rela- tados na área. ${ }^{14}$ Anticorpos IgM foram observados em soros de adultos ${ }^{10} \mathrm{e}$ de crianças $^{12}$ residentes na região, indicando infecção recente para esse vírus até o final da década de 80 .

Em 1990, relatou-se a presença de anticorpos neutralizantes, para a variedade IF do complexo VEE, em 24\% (6/25) dos soros de soldados que haviam retornado de treinamento em área silvestre do Vale do Ribeira. Vinte desses soldados tiveram doença febril por volta do sétimo dia após o retorno. Em dois deles detectaram-se anticorpos IgM para esse arbovírus. Foi o primeiro relato de doença humana, naturalmente adquirida, causada por esse agente. ${ }^{13}$

O objetivo do presente trabalho foi pesquisar a prevalência de anticorpos para arbovírus causadores de encefalite na população residente no bairro do Despraiado, interior da Estação Ecológica de Juréia-Itatins (EEJI). Em particular, houve interesse em investigar os membros de famílias residentes em contato estreito com o ambiente silvestre, para se verificar possíveis associações entre infecções por arbovírus e características individuais e também familiares dos investigados, uma vez que são escassos os trabalhos dirigidos à pesquisa de características familiares relacionadas a infecções por arbovírus.

Embora a área da EEJI apresente características semelhantes ao restante do Vale do Ribeira, com floresta tropical úmida praticamente preservada, nenhuma pesquisa referente à doença ou infecções inaparentes causadas por arbovírus havia sido realizada no local, até o momento. 


\section{MÉTODOS}

\section{Área e população estudadas}

A investigação foi realizada em 1990 na EEJI, localizada na região do Vale do Ribeira, sul do Estado de São Paulo, Brasil.

Como parte do sistema da Serra do Mar, a região é coberta por floresta latifoliada tropical úmida, abrigando flora e fauna bastante diversificadas. A atuação humana sobre a cobertura vegetal na região tem sido intensa, utilizando-se os terrenos para atividades agrícolas e pastoris. Entretanto, face ao difícil acesso, as áreas de encosta sofreram alterações menos intensas, verificando-se que a cobertura vegetal atinge áreas apreciáveis, dominando a paisagem local.

$\mathrm{Na}$ época do estudo, viviam na área estudada cerca de 300 famílias, num total aproximado de 1.200 pessoas. A pesquisa foi realizada entre 58 famílias moradoras do bairro do Despraiado, um dos núcleos habitados da reserva que apresentavam as condições já descritas.

Foram pesquisadas as seguintes características individuais: sexo, idade, naturalidade, estado civil, escolaridade, tempo de residência na área e residência anterior; e também o tipo de ocupação e de relacionamento com o meio ambiente.

Investigaram-se antecedente de encefalite, de febre amarela e de vacinação contra essas moléstias, embora a vacina de febre amarela não tenha sido aplicada na região desde 1953. A questão sobre antecedente de vacinação contra encefalite pelo vírus ROC foi introduzida porque durante a epidemia causada por esse agente foi aplicada uma vacina, em um estudo preliminar, em grupo de moradores do Vale do Ribeira, ${ }^{17}$ podendo influir no resultado da pesquisa de anticorpos.

Quanto às características das famílias, foram pesquisados o tipo de construção e de cobertura das moradias e a presença de anexos às casas, como galinheiros, paióis e chiqueiros. O contato com reservatórios e vetores foi caracterizado pela criação de animais domésticos, pela presença de insetos no domicílio e de animais silvestres, como tatus e gambás, no peridomicílio.

Investigou-se também a prática religiosa porque, no referido bairro, hé um templo no qual os serviços religiosos são realizados semanalmente, com comparecimento obrigatório da população praticante $(45,3 \%$ das famílias investigadas) em horário vespertino, quando existe grande atividade de mosquitos. Os indivíduos deslocavam-se a pé de casa para a igreja.

\section{Amostras de soro}

Os soros foram coletados - com consentimento por punção venosa, e conservados a $-20^{\circ} \mathrm{C}$. A pesquisa de anticorpos foi realizada em alíquota liofilizada dos soros na Unidade de Pesquisa de Arbovírus da Universidade de Yale (YARU).

Utilizou-se o teste de inibição de hemaglutinação ${ }^{3}$ (IH) para pesquisa de anticorpos para os vírus EEE, WEE, VEE, SLE, ROC e ILH. Os soros que apresentaram anticorpos IH foram submetidos ao teste de neutralização $(\mathrm{N})$ com redução de placas. ${ }^{6}$ Foi feita pesquisa de anticorpos da classe IgM para os arbovírus ROC, ILH e EEE, utilizando-se a técnica de Mac-Elisa descrita por Monath. ${ }^{18}$

Para o teste IH, os antígenos foram preparados de cérebro de camundongos recém-nascidos, pela técnica de extração com éter e acetona. Os soros foram tratados com acetona e absorvidos com hemácias de ganso. Os antígenos EEE, VEE e ROC foram preparados a partir de cepas virais isoladas no Vale do Ribeira. O antígeno WEE foi preparado a partir de vírus isolado no Rio de Janeiro. O antígeno SLE foi produzido a partir de agente isolado nos Estados Unidos e o antígeno ILH a partir da cepa original isolada em Ilhéus, Brasil.

O teste $\mathrm{N}$ foi realizado em culturas de células Vero. Para o teste foram utilizados os vírus SLE - Parton, Ilhéus - cepa original; VEE - SPAn 107237; EEE SPAn 111191 e ROC-SPH 34675.

Para a técnica de Mac-Elisa foram utilizados os antígenos EEE - cepa 76 V-25642, diluídos a 1:40, ROC - cepa original, diluído a 1:80 e ILH - cepa original, diluído a 1:80, fornecidos pelo "Center for Diseases Control" (CDC) dos EUA. Utilizou-se o anticorpo monoclonal 2A2C-3, conjugado à peroxidase, para pesquisa de anticorpos para EEE e o anticorpo monoclonal 6B6C-1, conjugado à peroxidase, para a pesquisa dos flavivírus. O substrato utilizado foi ABTS [2.2'-diazo-di (3-etil benzotiazolina sulfonato)].

\section{Análise estatística}

A associação estatística entre a presença de anticorpos para arbovírus e as características individuais e familiares dos indivíduos pesquisados, citadas anteriormente, foi pesquisada utilizando-se o teste do qui-quadrado. O nível de significância considerado foi menor ou igual a $5 \%$. 


\section{RESULTADOS}

\section{Pesquisa individual de anticorpos para arbovírus}

Foram pesquisados soros de 182 indivíduos das 58 famílias, $83(45,6 \%)$ do sexo feminino e $99(54,4 \%)$ do sexo masculino, com idades variando de 2 a 89 anos de idade. A maior parte das pessoas $(72,5 \%)$ tinha idade igual ou superior a 14 anos.

Nenhum dos entrevistados referiu antecedente de encefalite. Duas pessoas afirmaram ter recebido vacinação contra febre amarela. Uma delas tinha 51 anos de idade por ocasião da entrevista e nasceu e sempre residiu na região. Também não apresentou anticorpos para os flavivírus testados. O outro indivíduo, de 24 anos, natural do Estado de Goiás, vivia há mais de 10 anos no local e não apresentou anticorpos para os arbovírus testados.

A prevalência observada de infecções por arbovírus está apresentada na Tabela 1. Observou-se prevalência de $26,9 \%$ de anticorpos naquela população. A prevalência de infecções por alfavírus, representados pelos vírus EEE e VEE, foi de 21,4\%. Para os flavivírus testados: ROC, ILH e SLE, a prevalência encontrada foi de $12,6 \%$. Não foram observados anticorpos para o vírus WEE (Tabela 1).

Tabela 1 - Prevalência de anticorpos neutralizantes para arbovírus em residentes no bairro do Despraiado, Estação Ecológica de Juréia-Itatins, 1990.

\begin{tabular}{lcr}
\hline \multicolumn{1}{c}{ Arbovírus testados } & $\begin{array}{r}\text { Positivos } \\
\text { N }=182\end{array}$ & $\begin{array}{r}\text { Prevalência } \\
(\%)\end{array}$ \\
\hline Encefalite eqüina venezuelana (VEE) & 35 & 19,2 \\
Encefalite de St. Louis (SLE) & 13 & 7,1 \\
Rocio (ROC) & 6 & 3,3 \\
Encefalite eqüina do leste (EEE) & 4 & 2,2 \\
Ilhéus (ILH) & 4 & 2,2 \\
\hline Prevalência total* & 49 & 26,9 \\
\hline * 9 indivíduos infectados por mais de um agente (6 por 2; \\
por 3; e 1 por 4)
\end{tabular}

Verificaram-se anticorpos para os arbovírus testados em todas as faixas etárias (Tabela 2). Em particular, na faixa etária de 0 a 10 anos de idade, o grupo de 0 a 5 anos (compreendendo 13 crianças) não apresentou anticorpos. De uma forma geral, idade maior ou igual a 14 anos mostrou-se estatisticamente associada à infecção por arbovírus $\left(X^{2}=10,0-p<0,05\right)$.

Pessoas de ambos os sexos apresentaram anticorpos para os arbovírus testados (Tabela 2), mas não houve diferença estatisticamente significante entre a proporção de homens e de mulheres infectados $\left(X^{2}=0,62-p>0,05\right)$.
Do total de entrevistados, 84 (48,6\%) eram naturais do Vale do Ribeira, sendo que desses, 73 (42,2\%) viviam no bairro do Despraiado há mais de 10 anos, dos quais, 31 indivíduos apresentavam anticorpos para arbovírus. Na época da pesquisa, também residiam no local 89 pessoas naturais de outras localidades, sendo que 28 delas lá estavam havia mais de 10 anos. Quatorze dessas pessoas também tinham anticorpos para arbovírus. Houve associação estatisticamente significante $\left(X^{2}=10,1-p<0,05\right)$ entre infecção por arbovírus e ser natural da Região Administrativa de Registro, da qual fazem parte a região do Vale do Ribeira, onde se localiza a EEJI.

A relação entre ocupação e presença de anticorpos está apresentada na Tabela 3. Afirmaram ser lavradores 77 indivíduos, observando-se associação estatisticamente significante entre essa ocupação e infecções por arbovírus $\left(\mathrm{X}^{2}=8,1-\mathrm{p}<0,05\right)$. Dentre as 10 pessoas que referiram outras ocupações, 3 (professora, ajudante doméstico e comerciante) apresentaram anticorpos para arbovírus. Essas pessoas viviam na área de 6 meses a 2 anos, e referiram entrar raramente na mata. Dos outros 7 indivíduos, 2 (motorista e eletricista) viviam na área a menos de 6 meses e trabalhavam fora do bairro do Despraiado. O pastor evangélico freqüentava o bairro em dias de serviço religioso, mas não residia no local. $\mathrm{O}$ pedreiro e um dos funcionários públicos moravam na área entre 1 e 5 anos, mas entravam raramente na mata. Os dois outros funcionários públicos sempre viveram no bairro do Despraiado e referiram entrar diariamente na mata durante o dia.

Dos indivíduos entrevistados, 114 (66,7\%) referiram entrar na mata, sendo que 38 apresentavam anticorpos para arbovírus. Apenas 7, dentre os 57 $(33,3 \%)$ que não tinham esse hábito, apresentavam anticorpos. Quanto à frequiência com que entravam na mata, $47(41,2 \%)$ o faziam diariamente, $22(19,3 \%)$ entravam uma vez por semana, $6(5,3 \%)$ entravam apenas uma vez por mês e 39 (34,2\%) só raramente. O hábito de entrar na mata mostrou-se estatisticamente associado a infecções para arbovírus na população estudada $\left(\mathrm{X}^{2}=8,69\right.$ - $\left.\mathrm{p}<0,05\right)$, mas a frequiência com que isso acontecia não mostrou associação.

As características referentes ao estado civil e à escolaridade não apresentaram associação com infecções por arbovírus.

\section{Pesquisa familiar de anticorpos para arbovírus}

Foram encontrados soros positivos em membros de 36 das 58 famílias estudadas, representando uma prevalência de $62,1 \%$ de famílias com indivíduos apresentando anticorpos. 
Tabela 2 - Prevalência de anticorpos neutralizantes para arbovírus* segundo sexo e grupo etário dos moradores do bairro do Despraiado, Estação Ecológica de Juréia-Itatins, 1990

\begin{tabular}{|c|c|c|c|c|c|c|c|}
\hline \multicolumn{2}{|c|}{ Grupo etário } & \multicolumn{4}{|c|}{ Anticorpos para arbovírus } & \multicolumn{2}{|c|}{ Prevalência } \\
\hline \multirow[t]{2}{*}{ Anos } & \multirow[t]{2}{*}{$\mathrm{N}$} & \multicolumn{2}{|c|}{ Sexo masculino } & \multicolumn{2}{|c|}{ Sexo feminino } & \multirow[t]{2}{*}{$\mathrm{N}$} & \multirow[t]{2}{*}{$\%$} \\
\hline & & Positivos & Negativos & Positivos & Negativos & & \\
\hline $00-10$ & 39 & 2 & 17 & 1 & 19 & 3 & 7,7 \\
\hline $11-20$ & 36 & 5 & 15 & 4 & 12 & 9 & 25,0 \\
\hline $21-30$ & 29 & 5 & 9 & 5 & 10 & 10 & 34,5 \\
\hline $31-40$ & 23 & 3 & 12 & 3 & 5 & 6 & 26,1 \\
\hline $41-50$ & 13 & 2 & 5 & 3 & 3 & 5 & 38,5 \\
\hline $51-60$ & 23 & 6 & 6 & 3 & 8 & 9 & 39,1 \\
\hline $61 \mathrm{e}>$ & 19 & 6 & 6 & 1 & 6 & 7 & 36,8 \\
\hline Total** & 182 & 29 & 70 & 20 & 63 & 49 & 26,9 \\
\hline
\end{tabular}

* Vírus Ilhéus, Rocio, das encefalites eqüina do leste e Venezuelana e da encefalite de St. Louis.

** 9 indivíduos infectados por mais de um agente (6 por $2 ; 2$ por 3 ; e 1 por 4 )

Tabela 3 - Prevalência de anticorpos neutralizantes para arbovírus* segundo a ocupação dos moradores do bairro do Despraiado, Estação Ecológica de Juréia-Itatins, 1990.

\begin{tabular}{|c|c|c|c|c|c|c|c|}
\hline \multicolumn{3}{|c|}{ Ocupação } & \multicolumn{4}{|c|}{ Anticorpos para arbovírus } & \multirow{3}{*}{$\begin{array}{r}\text { Prevalência } \\
\% \\
\end{array}$} \\
\hline \multirow[t]{2}{*}{ Tipo } & \multicolumn{2}{|c|}{ Freqüência } & \multicolumn{2}{|c|}{ Sim } & \multicolumn{2}{|c|}{ Não } & \\
\hline & $\mathrm{N}$ & $\%$ & $\mathrm{~N}$ & $\%$ & $\mathrm{~N}$ & $\%$ & \\
\hline Lavrador & 77 & 48,7 & 30 & 66,7 & 47 & 41,6 & 39,0 \\
\hline Estudante & 38 & 24,1 & 5 & 11,1 & 33 & 29,2 & 13,2 \\
\hline Dona de casa & 33 & 20,9 & 7 & 15,6 & 26 & 23,0 & 21,2 \\
\hline Outras** & 10 & 6,3 & 3 & 6,6 & 7 & 6,2 & 30,0 \\
\hline Total & 158 & 100,0 & 45 & 100,0 & 113 & 100,0 & 28,5 \\
\hline
\end{tabular}

* Vírus Ilhéus, Rocio, das encefalites eqüina do leste e Venezuelana e da encefalite de St. Louis.

** Positivos: professora, comerciante, ajudante doméstico. Negativos: funcionários públicos (3), pastor evangélico, motorista, eletricista, pedreiro.

A natureza da moradia das famílias pesquisadas (49,1\% em alvenaria, $45,5 \%$ em madeira, e $5,4 \%$ de barro) ou o tipo de telhas utilizadas na cobertura das casas (61,8\% de fibrocimento e $38,2 \%$ de barro) não se mostraram estatisticamente associados à presença de moradores infectados por arbovírus. Da mesma forma, não houve associação entre a presença de anexos às residências, como galinheiro $(66,7 \%)$, chiqueiro $(25,5 \%)$ e paiol $(12,7 \%)$, e residentes com anticorpos para os arbovírus testados.

Quanto à relação com aves silvestres, reservatórios conhecidos de arbovírus, apenas uma família referiu "criar passarinho em gaiola". Verificou-se que nessa família a pessoa infectada tinha 89 anos de idade e apresentava anticorpos para VEE e EEE. Na casa vizinha, os infectados eram sua nora de 35 anos e seus netos de 8, 10 e 11 anos de idade, todos com anticorpos para o vírus VEE e todos com ampla frequiência à primeira moradia. As mulheres relataram ser donas de casa e as crianças, estudantes.

\section{DISCUSSÃO}

O teste de neutralização é a técnica sorológica de maior especificidade para pesquisa de infecções cau- sadas por arbovírus, especialmente por flavivírus Assim, os resultados obtidos com o teste de neutralização podem ser aceitos como padrão de referência diagnóstica para as infecções estudadas.

Foram encontrados anticorpos para todos os vírus testados, à exceção do vírus da encefalite eqüina do oeste (WEE). Esse agente nunca foi isolado no Vale do Ribeira. Entretanto, anticorpos neutralizantes e inibidores de hemaglutinação, reação monotípica para esse vírus, já haviam sido observados em trabalhadores residentes em ambiente silvestre naquela região. ${ }^{8}$ Também não foram observados anticorpos IgM, sugerindo que não havia infecção recente para os agentes testados naquela população.

Observaram-se indivíduos com anticorpos para os arbovírus testados em todas as faixas etárias, exceto no grupo de 0 a 5 anos de idade. A menor exposição aos vetores poderia explicar o fato de não se verificar nenhum infectado nesse grupo. $\mathrm{Na}$ faixa etária de 6 a 10 anos, a prevalência de anticorpos (3/26) foi significativamente mais baixa $(\mathrm{p}<0,05)$ em relação às faixas etárias superiores, evidenciando que a menor mobilidade dessas crianças 
as protege em relação a infecções por arbovírus, mesmo em local onde as casas estão junto ou dentro da mata e não têm janelas ou portas teladas. Além disso, nenhum indivíduo menor de 14 anos afirmou trabalhar, estando esse grupo, portanto, menos exposto a mosquitos no ambiente externo.

Quanto ao sexo, no bairro do Despraiado, homens e mulheres apresentaram prevalências semelhantes de infecções para os arbovírus pesquisados nos vários grupos etários. Esse fato decorre da proximidade com o ambiente silvestre, com ampla oportunidade de exposição a mosquitos vetores para todos os moradores, com exceção daqueles cuja mobilidade é mais restrita.

Quanto à ocupação, a maior prevalência de anticorpos para os arbovírus testados foi observada entre os lavradores. A segunda maior prevalência foi observada entre o grupo de dez indivíduos que exercia outras atividades. Dentre esses, os três que apresentaram anticorpos exerciam atividades que não favoreciam seu contato com vetores de arbovírus (professora, ajudante doméstico e comerciante), reforçando a hipótese de que naquele local todos os moradores estariam igualmente expostos a vetores de arbovírus pela proximidade com o ambiente silvestre. A ausência de anticorpos entre dois funcionários públicos, que referiram sempre ter vivido naquela área e que tinham o hábito de entrar na mata diariamente, pode ser explicada pelo fato da pesquisa ter sido dirigida apenas a arbovírus causadores de encefalite.

O tipo de construção e de cobertura das moradias daquela população não se mostrou associado à infecção pelos arbovírus pesquisados, mostrando que qualquer que fosse o padrão da moradia (alvenaria, madeira ou barro) não haveria diferença quanto à proteção contra reservatórios ou vetores. A prevalência significativamente menor de anticorpos em menores de 10 anos sugere que a transmissão intradomiciliar, se existente, foi baixa. Ressalte-se que, das três crianças infectadas nessa faixa etária, duas tinham contato com uma ave dentro de casa, sugerindo que a transmissão intradomiciliar pode ter ocorrido nesse caso pela proximidade com um reservatório de arbovírus.

A presença de anticorpos EEE e VEE nos moradores da residência onde havia passarinhos criados em gaiola sugere que essas pessoas podem ter se infectado no peridomicílio ou mesmo dentro de casa, uma vez que não frequientavam a mata devido à idade (8, 10, 11 e 89 anos). Cumpre lembrar que o vírus EEE já foi isolado de aves silvestres "residentes permanentes" do Estado de São Paulo ${ }^{15}$ e anticorpos inibidores de hemaglutinação, monotípicos para esse agente, foram detectados em aves silvestres no Vale do Ribeira. ${ }^{5}$ Também foram encontra- dos anticorpos hemaglutinantes para o subtipo IF do complexo VEE, o mesmo subtipo usado nos testes de neutralização do presente estudo, reação monotípica, em uma ave capturada naquela região. ${ }^{5}$

Os resultados confirmam achados anteriores, ${ }^{11,16} \mathrm{em}$ que características como ser natural do Vale do Ribeira ou exercer a atividade de lavrador, as quais pressupõem maior contato dos indivíduos com a mata e, portanto, com mosquitos vetores, já haviam sido associadas a infecções por arbovírus.

As prevalências de anticorpos para alfavírus e flavivírus foram, respectivamente, $21,4 \%$ e $12,6 \%$, não diferindo de resultados obtidos em inquérito anterior realizado em população adulta também residente em ambiente silvestre da região. ${ }^{8}$ A naturalidade dos indivíduos pesquisados em ambos os inquéritos e o tempo de residência na área sugerem que infecções humanas por alfavírus, entre residentes de ambiente silvestre, são mais prevalentes que as causadas por flavivírus. Em contrapartida, infecções por flavivírus parecem ser mais prevalentes que infecções por alfavírus em indivíduos que exercem suas atividades profissionais em geral fora da mata, como observado em inquérito realizado entre pescadores na região, ${ }^{10}$ quando a prevalência de anticorpos para flavivírus $(33,3 \%)$ foi maior do que a observada para alfavírus $(28,4 \%)$, reforçando a afirmação anterior.

Em relação aos alfavírus, é marcante a prevalência de anticorpos para VEE em relação aos outros arbovírus testados. A cepa SPAn107237, classificada como variedade IF do complexo VEE, ${ }^{6}$ isolada no Vale do Ribeira e utilizada para os testes de neutralização, foi a mesma responsável por doença em humanos na região. ${ }^{13}$

Concluindo: existe ampla circulação de arbovírus causadores de encefalite humana em população residente no bairro do Despraiado, EEJI. Esse fato impõe uma vigilância epidemiológica atuante sobre arbovírus, seus vetores e seus reservatórios na área. Aparentemente, a principal forma de exposição da população a vetores dos arbovírus estudados é o hábito de entrar na mata, uma vez que crianças, em especial menores de 5 anos, que não vão à escola e nem frequientam ambiente silvestre a trabalho, não apresentaram anticorpos. Os resultados sugerem a necessidade de outras investigações a respeito da responsabilidade de aves atuando no domicílio como reservatórios amplificadores de vírus e, portanto, como fatores de risco para indivíduos naturalmente menos expostos. A ausência de associações entre características familiares e presença de anticorpos para arbovírus pode estar ligada à casuística estudada, requerendo outros estudos em populações semelhantes. 


\section{AGRADECIMENTOS}

A Robert Shope, diretor da Unidade de Pesquisa de Arbovírus da Universidade de Yale, pelo apoio laboratorial. À Equipe Litoral Sul da Secretaria do

\section{REFERÊNCIAS}

1. Calisher $\mathrm{CH}$, Lopes OS, Coimbra TL, Francy DB, Jakob WL, Monath TP. Isolations of new Alpha and Bunyaviruses of Southern Brazil: proposed reclassification of serogroups. In: Anais do Simpósio Internacional sobre Arbovírus dos Trópicos e Febres Hemorrágicas; 1980; Belém, Brasil. Rio de Janeiro: Academia Brasileira de Ciências; 1982. p. 355-62.

2. Calisher $\mathrm{CH}$, Coimbra TL, Lopez OS, Muth DJ, Sacchetta LA, Francy DB et al. Identification of new Guama and Group C serogroup Bunyaviruses and an ungrouped virus from Southern Brazil. Am J Trop Med Hyg 1983;32:424-31.

3. Clark DH, Casals J. Techiques for hemagglutination and hemagglutination-inhibition with arthropod-borne viruses. Am J Trop Med Hyg 1958;7:561-73.

4. Coimbra TL, Nassar ES, Nagamori AH, Ferreira IB, Pereira LE, Rocco IM et al. Iguape, a newly recognized flavivirus from São Paulo State, Brazil. Intervirology 1993;36:144-52.

5. Ferreira IB, Pereira LE, Rocco IM, Marti AT, Souza LTM, Iversson LB. Surveillance of arbovirus infections in the atlantic forest region, State of São Paulo, Brazil. I. Detection of hemagglutination-inhibiting antibodies in wild birds between 1978 and 1990. Rev Inst Med Trop São Paulo 1994;36:265-74.

6. Fonseca BAL. Identification of an arthropod-borne of the Venezuelan Equine Encephalitis complex isolated in Sao Paulo, Brazil [dissertation]. New Haven: University of Yale; 1989.

7. Iversson LB, Travassos da Rosa APA, Travassos da Rosa J. Estudos sorológicos para pesquisa de anticorpos de arbovírus em população humana na região do Vale do Ribeira. II. Inquérito em pacientes do Hospital Regional de Pariquera-Açu, 1980. Rev Saúde Pública 1981;15:587-602.

8. Iversson LB, Travassos da Rosa APA, Travassos da Rosa J, Eleuterio GC, Prado, JA. Estudos sorológicos para pesquisa de anticorpos de arbovírus na população humana da região do Vale do Ribeira. I. Seguimento sorológico de grupo populacional residente em ambiente silvestre. In: Anais do Simpósio Internacional sobre Arbovírus dos Trópicos e Febres Hemorrágicas; 1980; Belém, Brasil. Rio de Janeiro: Academia Brasileira de Ciências;1982. p. 229-43.

9. Iversson LB, Travassos da Rosa APA, Travassos da Rosa J, Pinto GH, Macedo O. Estudos sorológicos para pesquisa de anticorpos de arbovírus em população humana da região do Vale do Ribeira. IV. Inquérito em escolares residentes no Município de Iguape, SP (Brasil). Rev Saúde Pública 1983;17:423-35.
Meio Ambiente, SP, por ter autorizado a realização da pesquisa e a colaboração de seus técnicos na coleta dos dados. À bióloga Maria Dulce Bianchi Rosa pela colaboração na realização dos testes imunoenzimáticos.
10. Iversson LB, Travassos da Rosa AM, Travassos da Rosa J, Macedo O. Seroepidemiological studies related to arbovirus in Ribeira Valley, Brazil. In: Abstracts of the 11th International Congress for Tropical Medicine and Malaria; 1984; Calgary, Canada. p. 68.

11. Iversson LB. Rocio encephalitis. In: Monath TP, editor. The arboviruses: epidemiology and ecology. Boca Raton: CRC Press;1988. v. 4. p. 77-92.

12. Iversson LB, Travassos da Rosa APA, Rosa MDB. Ocorrência recente de infecção humana por arbovírus Rocio na região do Vale do Ribeira. Rev Inst Med Trop São Paulo 1989;31:28-31.

13. Iversson LB, Travassos da Rosa APA, Rodrigues SG, Rosa MDB. Human disease caused by Venezuelan equine encephalitis sub-type IF in Ribeira Valley, Sao Paulo, Brazil. In: Abstracts of the Annual Meeting of the American Society of Tropical Medicine and Hygiene; 1990; New Orleans, USA, p.143.

14. Iversson LB, Coimbra TL, Travassos da Rosa APA, Monath TP. Use of immunoglobulin $M$ antibody capture enzyme-linked immunosorbent assay in the surveillance of Rocio encephalitis. Ciên Cult 1992;44:164-6.

15. Lopes OS, Sacchetta LA. Epidemiological studies on Eastern Equine Encephalitis virus in São Paulo, Brazil. Rev Inst Med Trop São Paulo 1974;16:253-8.

16. Lopes OS, Sacchetta LA, Coimbra TLM, Pinto GH, Glasser CM. Emergence of a new arbovirus disease in Brazil. II. Epidemiologic studies on 1975 epidemic. Am J Epidemiol 1978;108:394-401.

17. Lopes OS, Sacchetta LA, Nassar ES, Oliveira MI, Bisordi I, Suzuki A et al. Avaliação sorológica de vacina contra a encefalite humana causada pelo vírus Rocio. Rev Inst Méd Trop São Paulo 1980;22:108-13.

18. Monath TP, Nystron RR, Bailey RE, Calisher $\mathrm{CH}$, Muth DJ. Immunoglobulin $M$ antibody capture enzyme-linked immunosorbent assay for diagnosis of St. Louis encephalitis. J Clin Microbiol 1984;20:784-90.

19. Pessôa SB. Febre amarela. An Paul Med Cir 1956;71:411-7. 